Original Article

\title{
PHARMACOLOGICAL EVALUATION OF TRIPHALA CHURNA INSTREPTOZOTOCIN (I. C. V.) INDUCED DEMENTIA IN RATS
}

\author{
PURABI DEKA*, ARUN KUMAR \\ Division of Pharmaceutical Sciences, Shri Guru Ram Rai Institute of Technology and Science, Dehradun, Uttarakhand, India \\ Email: purabi3010@gmail.com
}

Received: 26 Sep 2017 Revised and Accepted: 22 Jan 2018

\begin{abstract}
Objective: The objective of the study was to investigate the memory improving activity of Triphala Churna hydro-methanolic fruit extract on learning and memory functions in Streptozotocin (I. C. V) induced dementia in rats by using morris water maze and elevated plus maze.

Methods: A total of 42 albino wistar rats weighing 80-100 g were randomized into 7 equal groups as follows: Normal control group received normal saline ( $1 \mathrm{ml} / \mathrm{kg}$ p. o.) for $24 \mathrm{~d}$, STZ treated group ( $3 \mathrm{mg} / \mathrm{kg}$, i. c. v) were administered in two dosage regimen i.e. on first day and third day.), Standard group: Streptozotocin (3 mg/kg i. c. v)+Vitamin E (100 mg/kg/day p. o.) were administered for $21 \mathrm{~d}$, Standard group: Streptozotocin (3 $\mathrm{mg} / \mathrm{kg}$ i. c. v)+Rivastigmine ( $2 \mathrm{mg} / \mathrm{kg} /$ day p. o.) were administered for $21 \mathrm{~d}$. The learning and memory-impaired rats were treated with Triphala Churna Formulation 1, Triphala Churna Formulation 2 and Triphala Churna Formulation 3 for $21 \mathrm{~d}$ (100 mg/kg p. o.). AchE activity, lipid peroxidation, superoxide dismutase, glutathione level of brain homogenate was estimated in Control/STZ (I. C. V)/Standard/Triphala Churna fruits extract treated rats.
\end{abstract}

Results: Administration of Triphala Churna fruits extract significantly restored learning and memory impairment induced by STZ (I. C. V) in the elevated plus maze and morris water maze. Furthermore, in the TPLC F2 and TPLC F3 treated group brain AchE level was decreased (P $\leq 0.01)$ as well as brain lipid peroxidation was also decreased $(\mathrm{P} \leq 0.001)$. Brain antioxidant enzymes such as glutathione level were increased $(\mathrm{P} \leq 0.001)$ in the TPLC1 and TPLC2 treated group when compared to the STZ treated group, TPLC F2 and TPLC F3 treated group showed significant (P $\leq 0.001$, $\mathrm{P} \leq 0.01$ ) increase in superoxide dismutase level.

Conclusion: Triphala Churna fruits extract has an improving effect on learning and memory impairment rats produced by Streptozotocin (I. C. V) and may have a useful effect in the treatment of dementia and Alzheimer's disease.

Keywords: Triphala Churna, AchE, Vitamin E, Rivastigmine, Streptozotocin (I. C. V.) and antioxidant

(C) 2018 The Authors. Published by Innovare Academic Sciences Pvt Ltd. This is an open-access article under the CC BY license (http://creativecommons.org/licenses/by/4.0/) DOI: http://dx.doi.org/10.22159/ijpps.2018v10i3.22795

\section{INTRODUCTION}

Acquisition of information and skill is defined as learning [1]. Through two processes behaviour is modified by experience-one is learning which means the acquisition of new knowledge about the environment and another is a memory which means its retention [2]. Dementia is a brain disorder denoted by a decrease in several higher mental functions such as memory, intellect, a personality that occurs serious impairments in daily life [3]. The prevalence of dementia increases with age, doubling every 5 y between the ages of 60 and 90 [4]. Dementia is induced by a disease that impairs tissues in the brain causing the destruction of brain functioning. Dementia is characterized by irreversible and reversible causes. Dementia due to long-term substance abuse, accumulation of blood beneath the outer covering of the brain that result of head injury, subdural hematoma, normal pressure hydrocephalus, toxic reactions like excessive alcohol or drug use, hypothyroidism, and nutritional deficiencies like vitamin B12 and folate deficiencies. Some of the irreversible and non-treatable cause of dementia involves diseases that cause degradation or loss of nerve cells in the brain such as PD, AD [4, 5] and HD, multi-infracts dementia (dementia because of multiple small strokes, also known as vascular dementia), infections that affect the spinal cord and brain, for example acquired-immune deficiency syndrome (AIDS) dementia complex and Creutzfeldt-Jakob disease. Some people have a combined type of dementia including both vascular dementia and AD. The most common symptoms that are mainly associated with dementia are psychosis, delirium from a sudden medical problem, aggression, insomnia or -sundowning (confusion in the early evening or late afternoon), anger, anxiety, pain from arthritis and depression [4, 6]. It represents a decrease in the previous level of functioning and it is also associated with impairment in psychiatric disturbances, behavioural and functional abilities $[7,8]$.
Intracerebroventricular (ICV) administration of streptozotocin (STZ) in rats is frequently employed to study experimental dementia by understanding some of the pathological aspects of SAD in humans, currently, [26]. Moreover, it has been well expressed that ICV-STZ rat model is targeting the functioning of brain IR signalling cascade. Decreased levels of glucose/energy metabolism especially in cerebral cortex and hippocampus areas in the brain have been investigated starting from $3 \mathrm{w}$ following ICV-STZ administration and hence mitochondrial dysfunction [14]. Further, a progressive trend towards oxidative stress has also been obtained starting as early as $1 \mathrm{w}$ following the ICV-STZ administration [27]. In addition to decreased energy metabolism and mitochondrial dysfunction, increased free radical generation, subsequent oxidative as well as nitrosative stress which are well revealed to impair learning and memory leading to cognitive dysfunction [28].

In ayurveda, triphala is well known as polyherbal formulation. In Indian system of medicine, it is used as a rasnayana drug [9]. Triphala is consists of the three dried fruits of trees and they are Indian gooseberry (Emblica officinalis Gaertn, family Euphobiaceae), Belleric myrobalan (Terminalia belericaLinn. Family, Combretaceae) and Chebulic myrobalan (Terminalia chebula Retzr. Family Combretaceae) $[10,11]$. It is composed equal proportion $(1: 1: 1)$ of these three fruits as described in ayurvedic formulary of india. Triphala is termed as tridosic rasnayana in ayurveda and it is having rejuvenating and balancing effect on three constitutional elements which regulate the human life (vata, pitta and kapha)[9]. The most commonly found polyphenolic compounds in the plant extracts are phenolic acids, flavonoids and tannins. $70 \%$ Methanolic extract of triphala exhibit antioxidative properties by the following order $T$. Chebula $>$ E. Officinalis $>T$. Bellerica. In their flavonoid content, the same order is followed, while in case of phenolic content the order is 
E. officinalis $>$ T. belerica $>$ T. chebula [12]. The aim of my study was a pharmacological evaluation of Triphala churna in streptozotocin (i. c. v.) induced dementia in rats.

\section{MATERIALS AND METHODS}

\section{Chemicals and reagents}

Acetic acid, Acetylthiocholine iodide, Bovine serum albumin, Calcium chloride, Chloral hydrate, Copper sulfate solution, Dextrose, Ethylene diamine tetra acetic acid (EDTA), Folin-ciocalteau reagent solution, Hydro-xylamine hydrochloride, Magnesium Chloride, Methanol, Nitro blue tetrazolium (NBT), Potassium chloride, Potassium phosphate dibasic, Protein estimation kit, Reduced glutathione, Streptozotocin(STZ), Sodium chloride (Nacl), Sodium potassium tartrate, Sodium hydroxide, Sodium dihydrogen phosphate, Sodium Carbonate, Sodium citrate, Superoxide dismutase colorimetric assay kit, Thiobarbituric acid (TBA), Trichloroacetic acid (TCA), Triton X-100 were purchased from Central drug house (P) Ltd New Delhi. Diethyl ether was purchased from SGRRITS; Vitamin E was purchased from Merck Limited, Goa; Rivastigmine was purchased from Sun Pharma Laboratories LTD, Sikkim.

\section{Procurement of triphala churna}

Emblica officinalis (Anwala Churna), Terminalia bellerica (Baheda Churna), and Terminalia chebula (Harad churna), manufactured at Vyas Pharmaceuticals, indore-452015 were obtained from the authorized Ayurvedic shop (Krishna Medical Hall, Paltan Bazar), local market, Dehradun, Uttarakhand.

\section{Animals}

Albino wistar rats weighing 80-100 g, were procured from animal house facility of Division of pharmaceutical science, Shri Guru Ram Rai Institute of Technology and Science, Patel Nagar, Dehradun. The care of laboratory animals and all the procedures on animals were performed in strict accordance with the CPCSEA, Ministry of forest and environment Government of India.

The protocol was approved by the Institutional Animal Ethics Committee (Registration No. 264/PO/ReBi/S/2002/CPCSEA) and will be carried out in accordance with the CPCSEA guidelines.

\section{Experimental protocol}

In present study 7 groups was employed and each group will be comprised of 6 animals.

Group I: Normal control group: Normal saline ( $1 \mathrm{ml} / \mathrm{kg}$ p. o. daily) was administered before evaluation of learning and memory for $24 \mathrm{~d}$.

Group II: Disease induced group: Streptozotocin (3 mg/kg, i. c. v) was administered in two dosage regimen i.e. on first day and third day.

Group III: Standard group: Streptozotocin ( $3 \mathrm{mg} / \mathrm{kg}$ i. c. v)+Vitamin $\mathrm{E}(100 \mathrm{mg} / \mathrm{kg} /$ day p. o.) was administered for $21 \mathrm{~d}$.

Group IV: Standard group: Streptozotocin $(3 \mathrm{mg} / \mathrm{kg}$ i. c. v)+Rivastigmine ( $2 \mathrm{mg} / \mathrm{kg} /$ day p. o.) was administered for $21 \mathrm{~d}$.

Group V: Streptozotocin (3 mg/kg i. c. v)+Triphala Churna Formulation 1 (100 mg/kg/day p. o.) was administered for $21 \mathrm{~d}$

Group VI: Streptozotocin ( $3 \mathrm{mg} / \mathrm{kg}$ i. c. v)+Triphala Churna Formulation 2 (100 mg/kg/day p. o.) was administered for $21 \mathrm{~d}$.

Group VII: Streptozotocin (3 mg/kg i. c. v)+Triphala Churna Formulation 3 ( $100 \mathrm{mg} / \mathrm{kg} /$ day p. o.) was administered for $21 \mathrm{~d}$.

\section{Extraction method}

The powder $(100 \mathrm{~g})$ of the individual normal air-dried fruits of $T$. chebula, T. belerica and $E$. officinalis was stirred using a magnetic stirrer with a 7:3 mixture of methanol: water $(500 \mathrm{ml})$ for $15 \mathrm{~h}$; the mixture was then centrifuged at $2850 \times g$ and the supernatant decanted. The process was repeated by adding the solvent with the precipitated pellet. The supernatants were collected, concentrated in a rotary evaporator $\left[250-200 \mathrm{mbar}\right.$ at $\left.37^{\circ} \mathrm{C}\right]$ and lyophilized. The yields for the plant's materials were $5.2 \mathrm{~g}, 3.8 \mathrm{~g}$ and $4.5 \mathrm{~g}$ for $T$. chebula, T. belerica and E. officinalis, respectively. The dried extracts were stored at $-20^{\circ} \mathrm{C}$ until use [12].

\section{Three formulations are:}

TPL Churna formulation 1 (T. Chebula: E. Officinalis: T. belerica)=1:1:1

TPL Churna formulation 2 (T. Chebula: $E$. Officinalis: $T$. belerica) $=2: 1: 1$

TPL Churna formulation 3 (T. Chebula: E. Officinalis: $T$. belerica) $=1: 2: 1$

\section{Streptozotocin (ICV STZ)-induced dementia}

Rats were anaesthetized with anaesthetic ether and I. C. V. injections were made with a hypodermic needle of $0.4 \mathrm{~mm}$ external diameter attached to a $10 \mu \mathrm{l}$ hamilton microlitre syringe. The needle was covered with a polypropylene tube except for $3 \mathrm{~mm}$ of the tip region so as to insert this portion of the needle perpendicularly through the skull into the brain of the rats. STZ was dissolved in freshly made artificial cerebrospinal fluid ACSF $(25 \mathrm{mg} / \mathrm{ml})$ solution. The injection site was $1 \mathrm{~mm}$ to right or left midpoint on the line drawn through to the anterior base of the ears. Injections were performed into the right or left ventricle randomly. Two doses of STZ $(3 \mathrm{mg} / \mathrm{kg})$ were administered by I. C. V. injection bilaterally. The second dose was administered $48 \mathrm{~h}$ after the first dose. The concentration was adjusted so as to deliver a maximum of $5 \mu \mathrm{l}$ in a single injection [13].

\section{Preparation of ACSF for STZ}

Artificial Cerebro Spinal Fluid is consists of $147 \mathrm{mmol} \mathrm{NaCl} ; 2.9$ mmol KCl; $1.6 \mathrm{mmol} \mathrm{MgCl}_{2} ; 1.7 \mathrm{mmol} \mathrm{CaCl}_{2}$ and $2.2 \mathrm{mmol}$ dextrose [14].

\section{Morris water maze}

\section{Acquisition trial}

In this study, spatial learning and memory of animals were tested in a morris water maze. The test was performed on day 20-23 and a probe trial was performed on day 24. It is comprised of a circular water tank $(180 \mathrm{~cm}$ diameter, $60 \mathrm{~cm}$ height $)$ filled with water $(25 \pm 1$ $\left.{ }^{\circ} \mathrm{C}\right)$ to a depth of $40 \mathrm{~cm}$. An escape platform $(12.5 \mathrm{~cm}$ in diameter and $38 \mathrm{~cm}$ high) was put in the pool $2 \mathrm{~cm}$ below the surface of the water. The escape platform was settled in the middle of one of the randomly selected quadrants of the pool and kept in the same position throughout the entire experiment. A non-toxic waterdispersible emulsion (milk) was used to render the water opaque. Four equally spaced locations around the edge of the pool (North, South, East, and West) were used as start points, which divided the pool into 4 quadrants. Without a platform, before the training started the rats were allowed to swim freely into the pool for 120 s. For each trial, each rat was put into the water at one of four starting positions, the sequence of which being selected randomly. During test trials, rats were placed into the tank at the same starting point, with their heads facing the wall and allowed to locate submerged platform within $120 \mathrm{sec}$. The rats received four consecutive daily training trials in the following $5 \mathrm{~d}$, with each trial having a ceiling time of $120 \mathrm{~s}$ and a trial interval of approximately $30 \mathrm{~s}$. The rat had to swim until it climbed onto the platform submerged underneath the water. After climbing onto the platform, the animal remained there for 30 s before the commencement of the next trial. If the rat failed to reach the escape platform within the maximally allowed time of $120 \mathrm{~s}$, it was guided with the help of a rod and allowed to remain on the platform for 30s. The time taken by rats to locate the hidden platform (latency in seconds) was measured. Animals were subjected to training trials for 5 consecutive days, the starting point was changed with each exposure as mentioned below and target quadrant (Q4 in the present study) remain constant throughout the training period.

\section{Memory consolidation test}

Twenty four hours after the acquisition phase, a probe test (day 24) was performed by removing the platform wherein the extent of memory consolidation was assessed. Rats were allowed to swim freely in the pool for $120 \mathrm{~s}$. The time spent by rats in target quadrant, which had previously contained the hidden platform, was noted. The time spent by rats in the target quadrant which indicated the degree of memory consolidation which had taken place after learning [15, $16,5]$. 


\section{Elevated plus maze}

An elevated plus-maze was used to test the cognitive function of animals. It is constituted of two opposite open arms $(50 \mathrm{~cm} \times 10 \mathrm{~cm})$ crossed with two closed arms of the same dimensions with $40 \mathrm{~cm}$ high walls. The arms were connected by a central square $(10 \mathrm{~cm} \times 10 \mathrm{~cm})$ and the apparatus was elevated $70 \mathrm{~cm}$ from the floor [17]. Memory acquisition and retention were tested using elevated plus maze test on days 23 and 24. Each rat was placed on the open arm, facing outwards. The time taken by the rat to enter the closed arm in the first trial (acquisition trial) on 23th day was noted and was called as initial transfer latency. Cut-off time was fixed at 90s and in case a rat did not move into the closed arm within this period, it was gently pushed into one of the closed arms and for $30 \mathrm{~s}$ it was allowed to explore the maze. The second trial (retention trial) was performed $24 \mathrm{~h}$ after the acquisition trial and retention transfer latency was noted. The retention trial latency was expressed as a percentage of initial trial latency [18].

\section{Biochemical parameter}

Brain collection and preparation of brain homogenate for estimation of AChE activity

The rats were decapitated by cervical dislocation under light anesthesia; brains are removed quickly and placed in ice-cold saline. $50 \mathrm{mg}$ of tissue was homogenized in $0.1 \mathrm{M}$ Phosphate buffer which is having $\mathrm{pH} 8(5 \mathrm{ml})$.

\section{Estimation of acetylcholinesterase (AChE) activity}

The method of AChE activity estimation is popularly known as Ellman's method, developed by George Ellman in 1961. The brain cholinesterase activity was estimated by providing an artificial chemical, acetylthiocholine (ATC). Thiocholine released because of the cleavage of ATC by AChE is allowed to react with 5, 5-dithio-bis(2, nitrobenzoic acid) (DTNB), which is reduced to thionitrobenzoic acid, a yellow coloured anion with absorption maxima at $412 \mathrm{~nm}$.

\section{Procedure}

Brains were removed quickly and placed in ice-cold saline. $50 \mathrm{mg}$ of tissue was homogenized in $0.1 \mathrm{M}$ Phosphate buffer which is having $\mathrm{pH} 8(5 \mathrm{ml})$. To a cuvette containing $2.6 \mathrm{ml}$ phosphate buffer $(0.1 \mathrm{M}$, $\mathrm{pH}$ 8), $0.4 \mathrm{ml}$ aliquot of the homogenate is added and $100 \mu \mathrm{l}$ of DTNB. Thoroughly the contents of the cuvette were mixed by bubbling air and absorbance is measured at $412 \mathrm{~nm}$ in a spectrophotometer. When absorbance obtains a stable value, it is recorded as the basal reading. $20 \mu \mathrm{l}$ of substrate i.e., acetylthiocholine is added and change in absorbance is recorded $[19,20]$.

\section{Preparation of Brain homogenate for antioxidant enzyme estimation}

Brain tissue samples were homogenized in $0.9 \% \mathrm{NaCl}$ by using tissue homogenizer [21].

\section{Estimation of lipid peroxidation}

Lipid peroxidation levels were measured by the Ohkawa et al. method. Taken $2 \mathrm{ml}$ of brain homogenate, add $2 \mathrm{ml}$ of $30 \%$ of trichloroacetic acid after that add $0.8 \%$ thiobarbituric acid reagent in a test tube. The tubes were covered with aluminium foil and kept in shaking water bath for half an hour at $80{ }^{\circ} \mathrm{C}$. After half an hour; the tubes were taken out and kept in ice-cold water for half an hour Keep test tube in cold water for half an hour. Then process homogenate was centrifuged at $3000 \mathrm{RPM}$ for $15 \mathrm{~min}$, the supernatant was separated out and absorbance was noted down at $535 \mathrm{~nm}$ against blank [21].

\section{Estimation of Brain glutathione}

Reduced glutathione estimation was done by the method of Sedlak and Lindsay, 1968. To $2 \mathrm{ml}$ of $10 \%$ of homogenate, $2.5 \mathrm{ml}$ of $0.02 \mathrm{M}$ EDTA was added and shaken vigorously. To $2 \mathrm{ml}$ of this mixture, $4 \mathrm{ml}$ of cold distilled water and $1 \mathrm{ml}$ of $50 \%$ trichloroacetic acid were added and was shaken for $10 \mathrm{~min}$. Thereafter, the content was centrifuged at $3000 \mathrm{x} g$ for $15 \mathrm{~min}$ following centrifugation, $2 \mathrm{ml}$ of the supernatant was mixed with $0.4 \mathrm{M}$ tris buffer ( $\mathrm{pH}$ 8.9). The whole solution was mixed well and $0.1 \mathrm{ml}$ of $0.01 \mathrm{M}$ DTNB was added, the absorbance was read within 5 min of addition of DTNB at $412 \mathrm{~nm}$ against reagent blank with no homogenate. For blank reading, the homogenate was substituted by $2 \mathrm{ml}$ of distilled water (Sedlak and Lindsay, 1968) [21].

\section{Estimation of superoxide dismutase}

SOD was estimated according to Kono method $1978.1 .3 \mathrm{ml}$ of solution A, $0.5 \mathrm{ml}$ of solution $\mathrm{B}$ and $0.1 \mathrm{ml}$ of solution $\mathrm{C}, 0.1 \mathrm{ml}$ of solution D were mixed and rate of NBT reduction was recorded for one minute at $560 \mathrm{~nm}$ on Schimadzu spectrophotometer UV120-01. $0.1 \mathrm{ml}$ of the supernatant was added to the test and reference cuvettes, which do not contain solution D. Finally, the \% inhibition in the rate of reduction of NBT was recorded as described above in U/g tissue. One enzyme unit was expressed as the inverse of the amount of protein $(\mathrm{mg})$ required inhibiting the reduction rate by $50 \%$ in one minute. The activity was calculated using the $\%$ inhibition in a gram of tissue and expressed in Unit/g tissue [22, 23].

\section{Estimation of total protein}

According to the method of Lowry OH, et al. 1951 total protein was done. Total amount of brain total protein was expressed in $\mathrm{mg}$ [15].

\section{Statistical analysis}

The statistical analysis was carried out using prism graph pad 7 software. All values were represented as mean \pm SEM. Multiple comparisons between different groups was performed using oneway analysis of variance followed by Tukey's test for all biochemical evaluation except in morris water maze.

\section{RESULTS}

\section{Pharmacological study}

\section{Behavioral estimation}

Effect of STZ (i. c. v.) on escape latency time (ELT) and time spent in target quadrant (TSTQ) on morris water maze in rats

Control group showed a significant decrease $(p \leq 0.001)$ in day 4 ELT when it was compared to its ELT on day 1(fig. 1). In control group, rats spent significantly $(\mathrm{p} \leq 0.001)$ more time in the target quadrant (Q4) when it compared to the time spent in other quadrants $(\mathrm{Q} 1, \mathrm{Q} 2$, Q3) (fig. 2). STZ treated group showed a significant $(p \leq 0.001)$ increase in ELT when it compared to ELT of the control group (fig. 1) on the same day. STZ treated rats also showed significant $(\mathrm{p} \leq 0.001)$ decrease in time spent in target quadrant (TSTQ) when it compared time spent in target quadrant (Q4) of control group (fig. 2).

Effect of Triphala Churna fruits extract on escape latency of streptozotocin-treated rats in morris water maze (MWM)

Vitamin $\mathrm{E}$ and Rivastigmine treated group significantly $(\mathrm{P} \leq 0.001)$ improve the ELT when compared with STZ treated group. TPLC F2 showed more significant result $(\mathrm{P} \leq 0.001)$ when compared to the STZ treated group (fig. 3).

Effect of Triphala Churna fruits extract on time spent on targeted quadrant (TSTQ) of streptozotocin-treated rats in morris water maze (MWM)

When we compared among the Control, STZ, STZ+Vitamin E, STZ+Rivastigmine, STZ+TPLC F1, STZ+TPLC F2, STZ+TPLC F3 during time spent in targeted quadrant there is a significance difference. Administration of Vitamin $\mathrm{E}$ and Rivastigmine showed high significance at $(\mathrm{P} \leq 0.001)$ when compared with STZ treated group. TPLC F1, TPLC F2, TPLC F3 (100 mg/kg p. o.) showed high significance at $(\mathrm{P} \leq 0.001)$ when compared with STZ treated group (fig. 4).

Effect of Triphala Churna fruits extract on transfer latency (TL) of streptozotocin-treated rats in elevated plus maze (EPM)

Treatment with streptozotocin showed significant $(P \leq 0.001)$ increase in TL time when compared with control group. Hydromethanolic extract of TPLC F1, TPLC F2, TPLC F3 $(100 \mathrm{mg} / \mathrm{kg} \mathrm{p.} \mathrm{o.)}$ and standard (Vitamin E, Rivastigmine) significantly $(\mathrm{P} \leq 0.001)$ reduce TL time when compared to STZ treated group. The effect of TPLC F2 (100 mg/kg p. o.) was noticed to be comparable to standard (Vitamin E) treated group (fig. 5). 


\section{Biochemical estimation}

Effect of Triphala Churana fruits extract on brain AchE activity of streptozotocin (i. c. v.) treated rats

Treatment with streptozotocin showed significant $(P \leq 0.001)$ increase in brain AchE activity when compared to control group. The rats were treated with Vitamin $\mathrm{E}$ and Rivastigmine showed significant $(\mathrm{P} \leq 0.001)$ decrease in AchE activity when compared to streptozotocin treated group, whereas a significant $(\mathrm{P} \leq 0.01)$ decrease in AchE activity was observed in the TPLC F3 and TPLC F2 treated group. TPLC F1 group showed low significance at $\mathrm{P} \leq 0.05$ while compared to the STZ treated group (fig. 6).

Effect of Triphala Churana fruits extract on lipid peroxidation of streptozotocin (i. c. v.) treated rats

Lipid peroxidation study showed that streptozotocin treated group showed significant $(\mathrm{P} \leq 0.001)$ increase in MDA level when compared to control group. Standard (Vitamin E and Rivastigmine) and TPLC F2, TPLC F3 treated group were able to prevent the elevated MDA level, showed significant at $(\mathrm{P} \leq 0.001)$ and $T P L C$ F1 showed significance at $(\mathrm{P} \leq 0.01)$ decrease in MDA level when compared to streptozotocin treated group (fig. 7).
Effect of Triphala Churna fruits extract on level of glutathione streptozotocin treared rats

Streptozotocine treated group showed significant $(\mathrm{P} \leq 0.001)$ decrease in glutathione level when compared with control group. Whereas, standard (Vitamin E and Rivastigmine) treated showed significant $(\mathrm{P} \leq 0.001)$ increase in activity of glutathione when compared to streptozotocin treated group. In another hand TPLC F1, TPLC F2 treated group showed significant $(P \leq 0.001)$ increase in glutathione level when compared to STZ group but results are not better than the standard treated group. TPLC F1 showed low significance $(\mathrm{P} \leq 0.01)$ when compared to STZ group (fig. 8).

Effect of Triphala Churna fruits extract on level of SOD streptozotocin-treated rats

Streptozotocin-treated group showed significant $(\mathrm{P} \leq 0.001)$ decrease in SOD level when compared with control group. Whereas, standard (Vitamin E and Rivastigmine) treated showed significant $(\mathrm{P} \leq 0.001)$ increase in activity of SOD level when compared to streptozotocin treated group. In another hand TPLC F2 and TPLC F3 treated group showed significant $(\mathrm{P} \leq 0.001, \mathrm{P} \leq 0.01)$ increase in SOD level when compared to the standard treated group but results are not better than standard treated group (fig. 9).

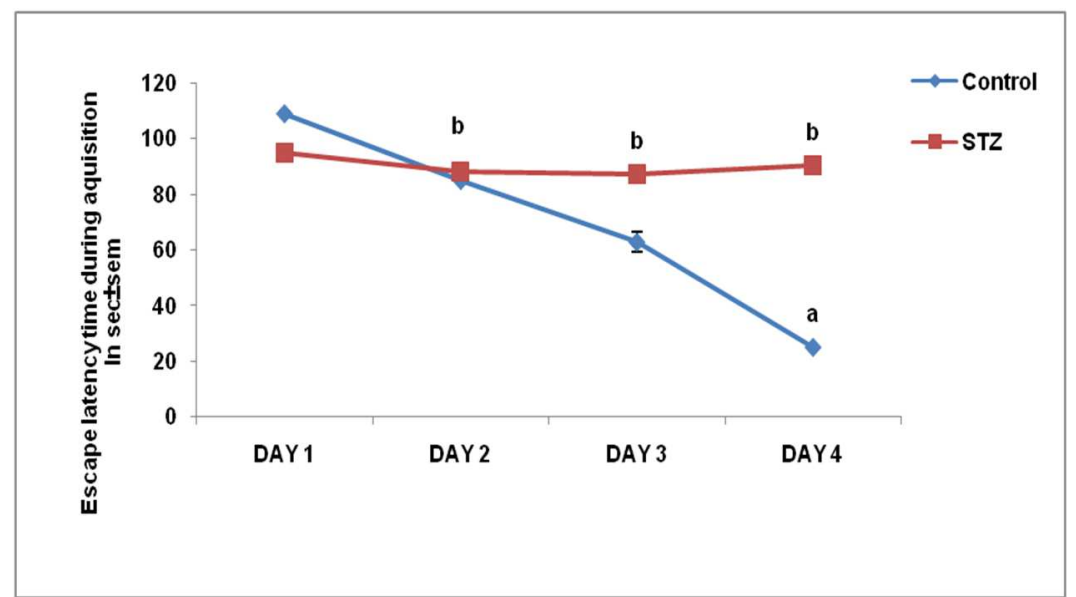

Fig. 1: Effect of STZ (i. c. v) on escape latency time (ELT) during acquisition trials on morris water maze in rats. Each group (n=6) represents mean \pm standard error of means (SEM), $a=p \leq 0.001$ Vs. ELT on the first day of the control group, $b=p \leq 0.001$ Vs. ELT on the same day of the control group. STZ-Streptozotocin

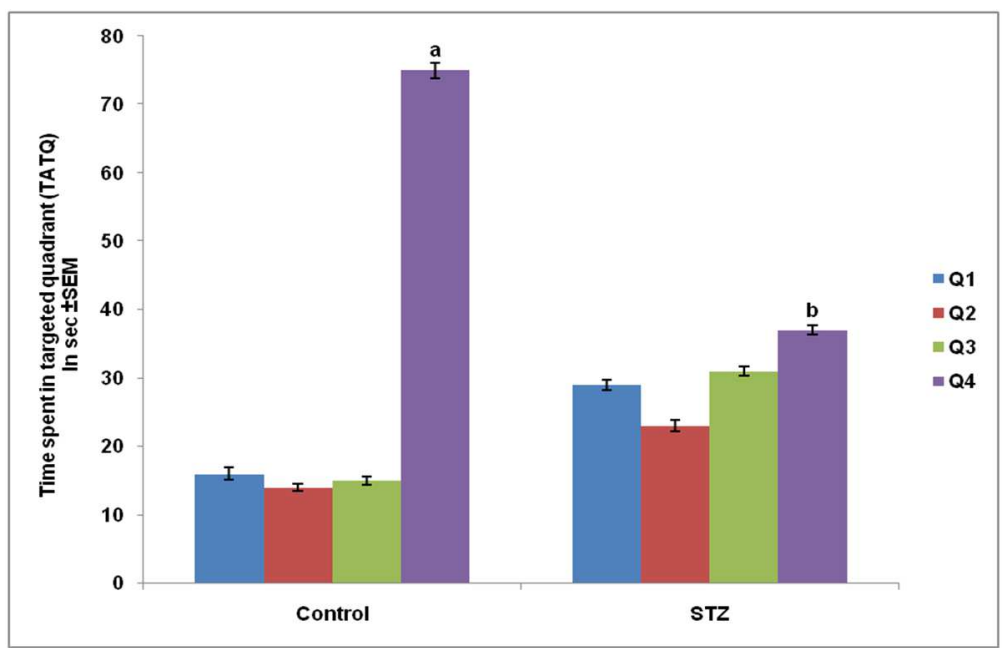

Fig. 2: Effect of STZ (i. c. v) on time spent in the target quadrant (TSTQ) during retrieval trial on morris water maze in rats. Each group $(n=6)$ represents mean \pm standard error of means (SEM), $a=p \leq 0.001$ vs. time spent in another quadrant in STZ treated group, $b=p \leq 0.001$ vs. time spent in the target quadrant (Q4) of STZ treated group. STZ-Streptozotocin 


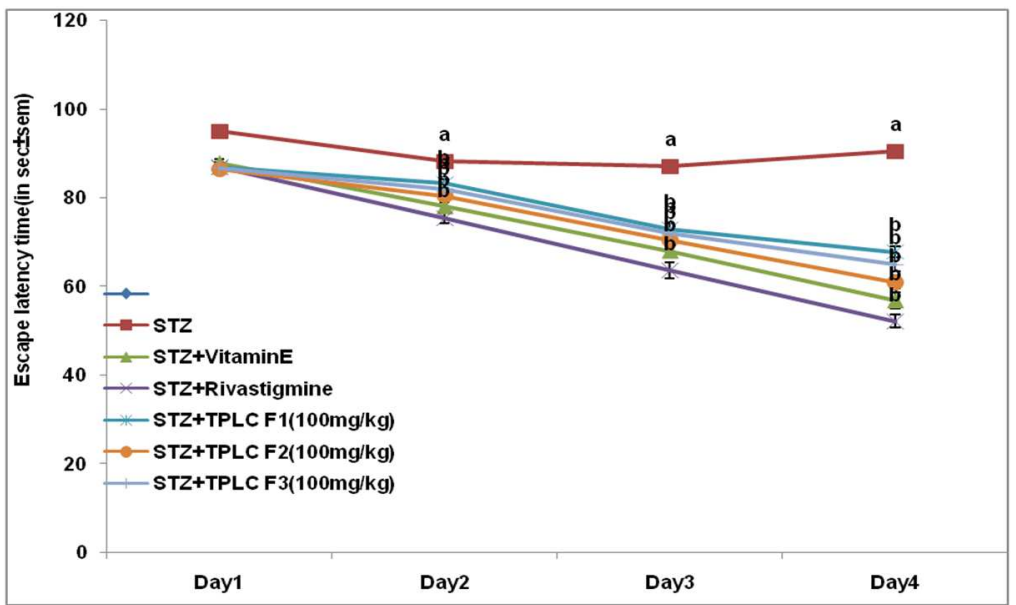

Fig. 3: Effect of Triphala Churna fruits extract on escape latency of streptozotocin-treated rats on morris water maze (1-4 d) in sec. Each group ( $n=6)$ represents mean \pm standard error of means (SEM), $a=p \leq 0.001$ vs. ELT on the first day of STZ (i. c. v) treated group, $b=p \leq 0.001$ vs. ELT of STZ (i. c. v) treated group. STZ-Streptozotocin, TPLC-Triphala Churna, F1-Formulation 1, F2-Formulation 2, F3-Formulation 3

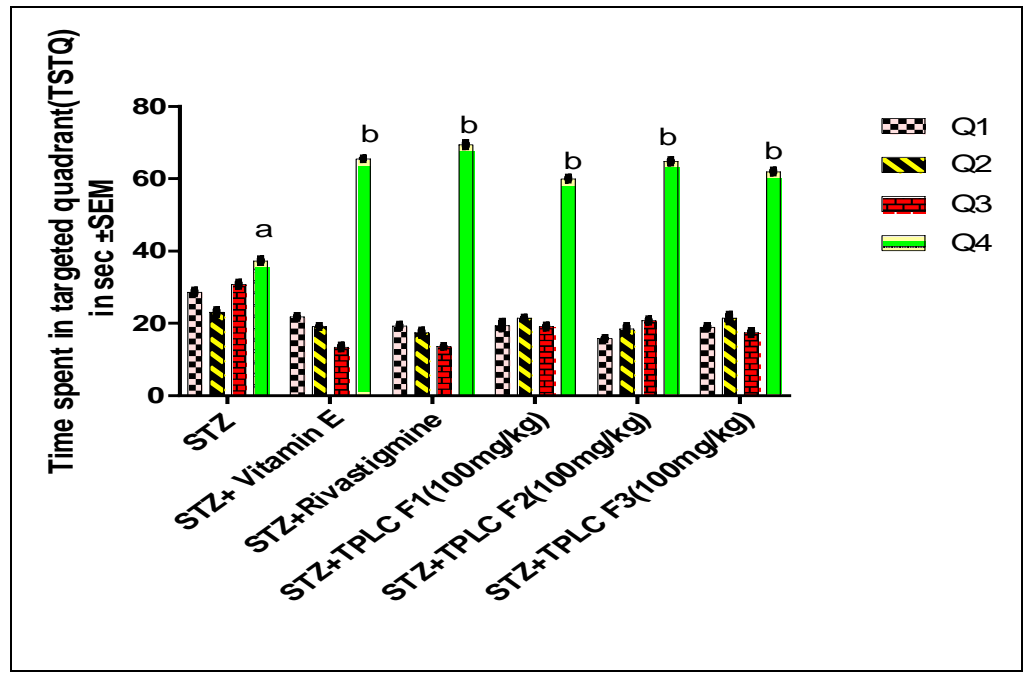

Fig. 4: Effect of Triphala Churna fruits extract on time spent in target quadrant (TSTQ) during retrieval trial in STZ treated rats on morris water maze. Each group $(n=6)$ represents mean \pm standard error of means (SEM). $a=p \leq 0.001$ vs. time spent in another quadrant in STZ treated group, $b=p \leq 0.001$ vs. time spent in target quadrant (Q4) of STZ treated group. STZ-Streptozotocin, TPLC-Triphala Churna, F1Formulation 1, F2-Formulation 2, F3-Formulation 3

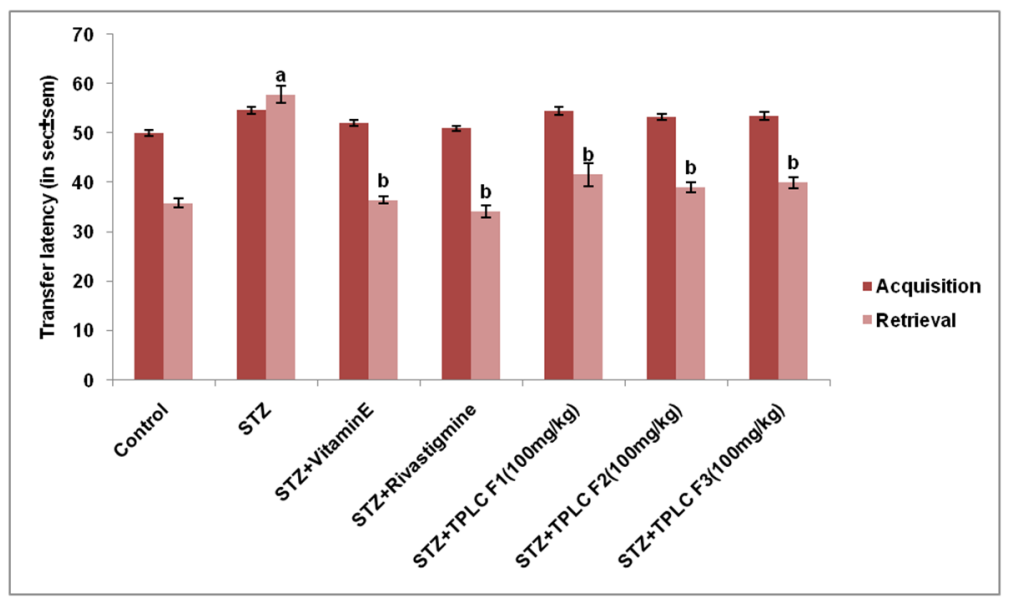

Fig. 5: Effect of Triphala Churna fruits extract on transfer latency (TL) of streptozotocin-treated rats on elevated plus maze (acquisition and retrieval in $\mathbf{s e c} \pm \mathrm{SEM}$ ). Each group $(\mathrm{n}=6)$ represents mean \pm standard error of means (SEM), $a=P \leq 0.001$ Vs control group, $b=P \leq 0.001 \mathrm{Vs}$ STZ treated group. STZ-Streptozotocin, TPLC-Triphala Churna, F1-Formulation 1, F2-Formulation 2, F3-Formulation 3 


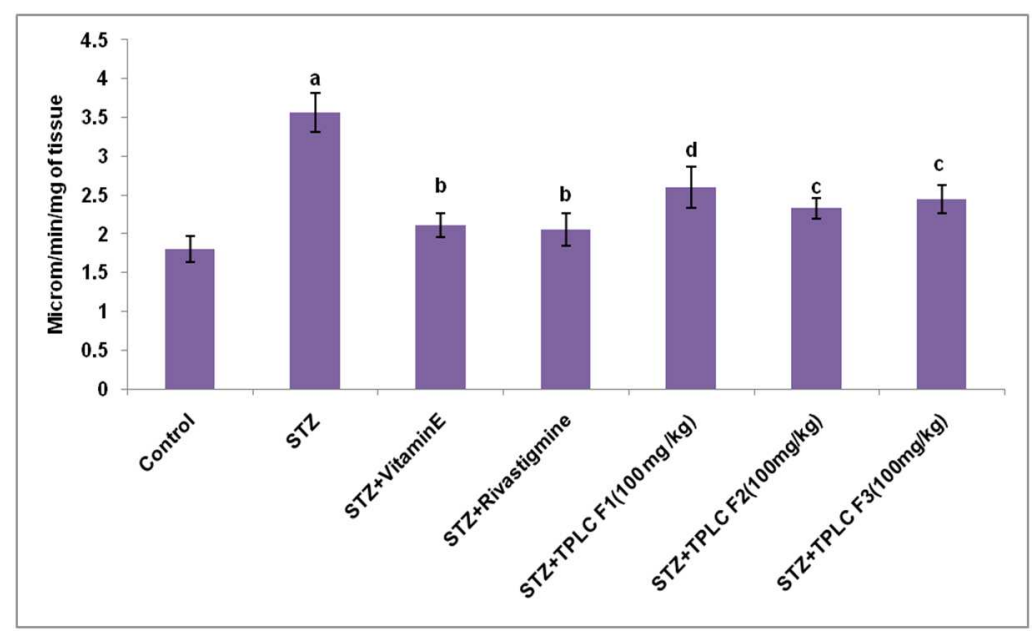

Fig. 6: Effect of Triphala Churna fruits extract on brain cholinesterase activity in streptozotocin-treated rats. Each group (n=6) represents mean \pm standard error of means (SEM), $a=P \leq 0.001$ versus control group, $b=P \leq 0.001$ versus $S T Z$ treated group, $c=P \leq 0.01$ versus $S T Z$ treated group, $d=P \leq 0.05$ versus STZ treated group. STZ-Streptozotocin, TPLC-Triphala Churna, F1-Formulation 1, F2-Formulation 2, F3Formulation 3

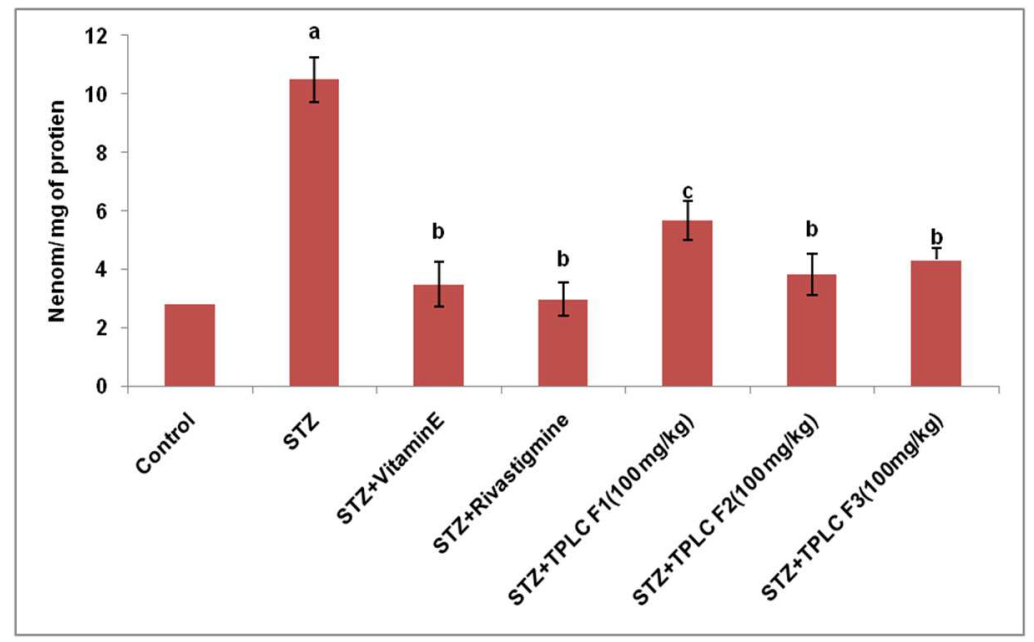

Fig. 7: Effect of Triphala Churna fruits extract on lipid peroxidation in streptozotocin-treated rat's brain. Each group (n=6) represents mean \pm standard error of means ( $S E M), a=P \leq 0.001$ versus control group, $b=P \leq 0.001$ versus $S T Z$ treated group, $c=P \leq 0.01$ versus $S T Z$ treated group. STZ-Streptozotocin, TPLC-Triphala Churna, F1-Formulation 1, F2-Formulation 2, F3-Formulation 3

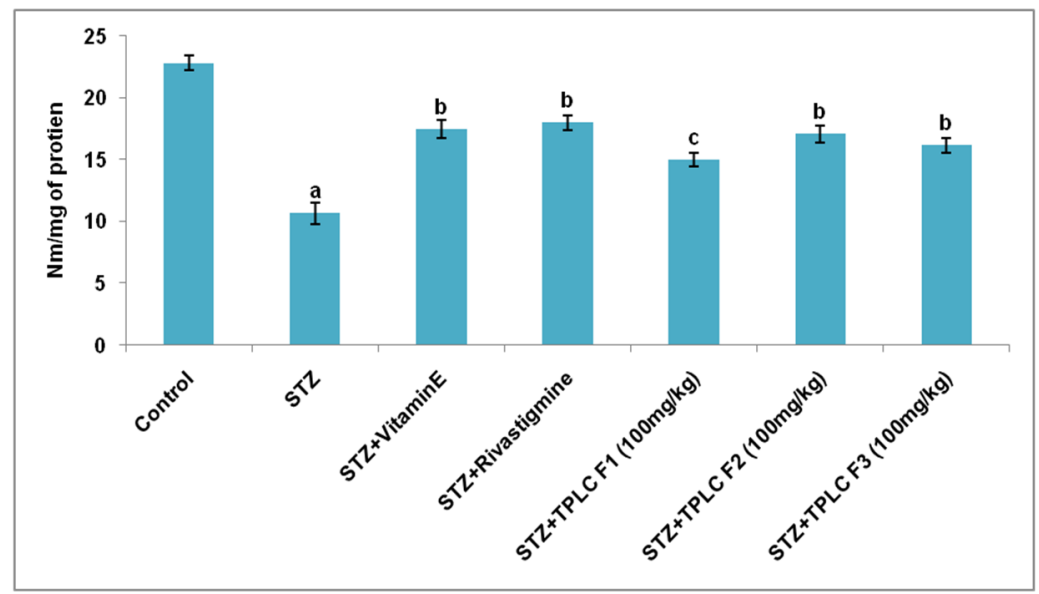

Fig. 8: Effect of Triphala Churna fruits extract on the level of glutathione in streptozotocin-treated rat's brain. Each group (n=6) represents mean \pm standard error of means ( $S E M), a=P \leq 0.001$ versus control group, $b=P \leq 0.001$ versus $S T Z$ treated group, $c=P \leq 0.01$ versus STZ treated group. STZ-Streptozotocin, TPLC-Triphala Churna, F1-Formulation 1, F2-Formulation 2, F3-Formulation 3 


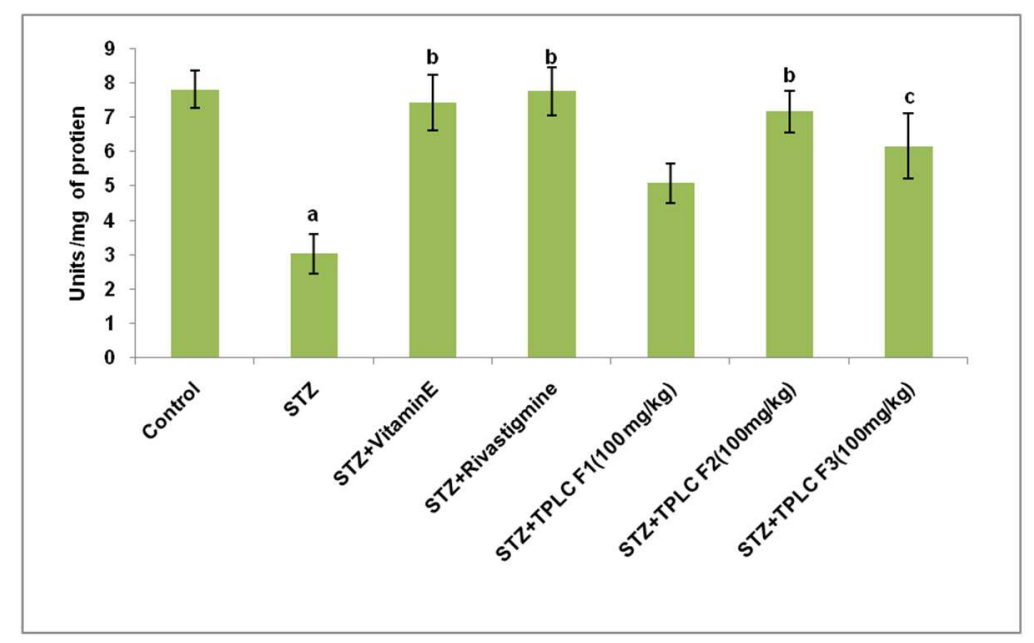

Fig. 9: Effect of Triphala Churna fruits extract on level of superoxide dismutase in streptozotocin-treated rat's brain. Each group (n=6) represents mean \pm standard error of means $(S E M), a=P \leq 0.001$ versus control group, $b=P \leq 0.001$ versus $S T Z$ treated group, $c=P \leq 0.01$ versus STZ treated group. STZ-Streptozotocin, TPLC-Triphala Churna, F1-Formulation 1, F2-Formulation 2, F3-Formulation 3

\section{DISCUSSION}

Dementia is an umbrella term that encompasses symptoms of a chronic progressive cognitive decline usually affecting memory and almost always a judgment, decision-making, and relationships with others. Dementia can be divided into cortical and subcortical forms. Alzheimer's disease is a form of cortical dementia, as is creutzfeldtJakob disease (CJD). In subcortical dementia, structures below the cerebral cortex are affected or damaged, such as occurs in Parkinson's disease. In multi-infarct dementia both the cortical and subcortical parts of the brain are affected. Dementia can also be divided into reversible causes such as hypothyroidism, normal pressure hydrocephalus, and vitamin B12 deficiency, and irreversible causes such as alzheimer's disease. The most common causes of progressive dementia are alzheimer's disease, vascular dementia, and dementia with lewy bodies, frontotemporal dementia, parkinson 's disease, and wernicke-korsakoff dementia. Alzheimer's disease (AD) is a neurodegenerative disease which involves progressive and irreversible loss of neurons in various regions of the brain. It constitutes approximately $60 \%$ of all cases of dementia and is more common in women. It is characterized by impairment of memory and at least one cognitive domain (aphasia, apraxia, agnosia, executive function) $[24,25]$. Dementia is one of the characteristics of Alzheimer's disease, Donepezil and Galantamine are the established drugs to treat dementia associated with Alzheimer's disease [33].

Oxidative stress, which occurs when there is an imbalance between antioxidants and reactive oxygen species within a cell, may lead to permanent cellular damage. The polyunsaturated fatty acids of membrane lipids are prime targets for reactive oxygen species and peroxide radicals. The central nervous system is particularly vulnerable to lipid peroxidation because of its high lipid content and unusually high proportion of polyunsaturated fatty acids. In AD patients, concentrations of malondialdehyde, a measure of lipid peroxidation, are elevated. Lipid peroxidation may promote the formation of additional reactive oxygen species and enhance protein and DNA oxidative damage.

Vitamin E has an excellent safety record [32]. Vitamin E is a necessary nutrient in human body and it is a popular antioxidant substance. It decreases reactive oxygen species activity and free radicals like other antioxidants. Vitamin E prevents or delays memory impairments that accompany many conditions such as cerebral ischemic injury, mental stress, aging, diabetes, alzheimer's disease, stroke etc [29].

Rivastigmine is a carbamate-based, reversible, non-competitive inhibitor of both AChE and butyrylcholinesterase. Its inhibitory effect is of long duration and is relatively specific to the central nervous system. Rivastigmine is approved for the mild-to-moderate $\mathrm{AD}$ and for mild-to-moderate dementia related to Parkinson's disease [30]. Rivastigmine provides a distinct benefit for AD, and PD, patients with dementia [31].

Streptozotocin significantly impaired the learning and memory, after

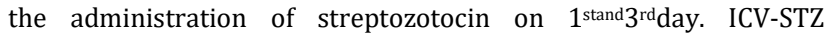
treatment causes a marked reduction in brain glucose/energy metabolism and shows a progressive trend towards oxidative stress. ICV-STZ generated NMDA receptor overactivation, mitochondrial dysfunction, decrease neuronal glucose which causes a decrease in Ach, ChAT, ATP and increase in AchE etc. These lead to oxidative damage, DNA damage, neuroinflammation after that it causes learning and memory impairment and neurotoxicity.

Morris water maze test and elevated plus maze are employed as most extensively accepted model for evaluation of learning and memory. Rats were taken lesser seconds in transfer latency (retrieval) as compared to transfer latency (acquisition) it means standard and Triphala Churna showed better result in retrieval day. In Morris water maze, after the administration of standard and Triphala Churna significant reduction in escape latency time and also increase time spent in target quadrant on $5^{\text {th }} \mathrm{d}$.

The AchE elevated level in alzheimer's disease has results in the hypothesis that learning and memory impairment is linked to cholinergic degradation. Therefore precise approach for treatment of alzheimer's disease is to increase Ach level in the brain region.

The present study shows that a significant increase in AchE in streptozotocin administered rats. A significant decrease AchE function has been showed in the rats treated with Triphala Churna especially in Triphla Churna Formulation2 (100 mg/kg/day p. o.) dose.

Excessive synthesis of free radicals or the reactive oxygen species can lead to the damage of the cell and tissue of the brain which leads to cell death. The classes of main defense antioxidant that prevent the generation of new free radical species are glutathione and SOD. The further study concluded that the oxidative stress is induced by streptozotocin (i. c. v.) on $1^{\text {st }}$ and ${ }^{3 r d}$ day. In rats streptozotocin decrease the SOD and glutathione level. After the administration of Vitamin E, Rivastigmine and Triphala Churna showed a significant increase in SOD and glutathione level.

An elevated level of lipid peroxidation in the brain shows the neuronal damage. The decrease of antioxidant defense and increase in free radical generation deteriorates the pro-oxidant and antioxidant balance regulation which leads to oxidative stress and cell death.

The oxidative stress produced by streptozotocin has been linked with the increased amount of lipid peroxidation. The administration 
of a hydro-methanolic extract of Triphala Churna in my experiment was potentially active in reducing the oxidative stress. This indicates that Triphala Churna fruits extract has a potent antioxidant activity to reduce the oxidative stress induced lipid peroxidation. Triphal Churna Formulation2 $(100 \mathrm{mg} / \mathrm{kg} / \mathrm{d} \quad$ p. o. $)$ showed more improvement in dementia comparison to the other test groups.

\section{CONCLUSION}

The aim of the present study was to evaluate the pharmacological effect of Triphala Churna on streptozotocin-induced dementia in rats. This was proved by the following parameters.

The phytochemical constituents in Triphala Churna are phenolic acids, flavonoids, tannins etc. It contains gallic acid, tannic acid, syringic acid, epicatechin, ascorbic acid, aellagitann,interchebulin along with punicalagin, terflavin-A, shikimic, tricontanoic, palmitic acids, beta-sitosterol, daucosterol, triterpene chebupentol etc.

Disease induced STZ (i. c. v.) treated rats shows a significant increase in the AchE activity. Whereas, this increased activity is reverse by treatment of group with Triphala Churna and standard (Vitamin E, Rivastigmine). Reduction in the AchE activity by Triphala Churna fruits extract may directly or indirectly related to the cholinergic dependent learning and memory.

After administration of STZ (i. c. v), disease control rats showed a decrease in free radical scavenging enzymes such as SOD and glutathione. In another hand after the administration of TPLC, free radical scavenging enzyme restored significantly.

In present study treatment by TPLC decreases the lipid peroxidation. Hence, it was concluded the Triphala Churna have a potential role in the management of learning and memory impairment.

\section{ABBREVIATIONS}

Acetylcholine (Ach), artificial cerebro spinal fluid(ACSF), alzheimer Disease(AD), adenosine triphosphate (ATP), huntington's disease(HD), parkinson's disease (PD), intra cerebro ventricular(ICV), N-methyl-D-aspartate (NMDA), streptozotocin (STZ), sporadic alzheimer disease(SAD), triphala churna formulation (TPLCF), superoxide dismutase (SOD)

\section{AUTHORS CONTRIBUTIONS}

Design, experimental part of the work, analysis of the results, writing and development of the manuscript was done by Purabi Deka. Supervision of the research program was done by Dr. Arun Kumar.

\section{CONFLICT OF INTERESTS}

Authors declared no conflict of interests

\section{REFERENCES}

1. Dua GS, Prasad DN, Tripathi AC, Gupta R. Role of traditional medicine in Neuropsychopharmacology. Asian J Pharm Clin Res 2009;2:72-8.

2. Kandel ER, Schwartz JH. Molecular biology of learning: modulation of transmitter release. Science 1982;218:433-43.

3. Knapp M, Comas-Herrera A, Somani A, Banerjee S. Dementia: summary report for the National Audit Office international comparisons. PSSRU; 2007. p. 1-18.

4. Mehan S, Arora R, Sharma D, Meena H, Sharma G, Vyas T. Dementia: a complete literature review on various mechanisms involves in pathogenesis and an intra cerebro ventricular streptozotocin-induced alzheimer's disease. Int J Pharma Prof Res 2013;4:937-52.

5. Tiwari V, Kuhad A, Bishnoi M, Chopra K. Chronic treatment with tocotrienol, an isoform of Vit E, prevents intracerebroventricular streptozotocin induced cognitive impairement and oxidative-nitrosative stress. Pharmacol Biochem Behavi 2009;93:183-9.

6. Kuljis OR. Advances in the Understanding of pathophysiological mechanisms in alzheimer disease applied to new treatment paradigms. Appl Neurol 2007;20:77-89.

7. Melesie G, Dinsa H. A literature review on: pathogenesis and management of dementia due to AD. Bio-Gen J 2013;1:18-31.
8. Kumar N, Sharma S. Evaluation of the therapeutical potential of Kinnow fruit juice on scopolamine-induced amnesic rats. Int J Univers Pharm Bio Sci 2016;5:2319-8141.

9. Gowda DV, Muguli G, Rangesh PR, Deshpan DR. Phytochemical and pharmacological action of triphala: ayurvedic formulation a review. Int J Pharm Sci 2012;15:61-5.

10. Rasool M, Sabin EP. Anti-inflammatory effect of the indian ayurvedic herbal formulation Triphala on adjuvant-induced arthritis in mice. Phytother Res 2007;21:889-94.

11. Sandhyaa T, Lathikaa KM, Pandeyb BN, Mishraa KP. Potential of traditional ayurvedic formulation, Triphala, as a novel anticancer drug. Canlet 2006;231:206-14.

12. Hazra B, Sarkar R, Biswas S, Mandal N. Comperative study of the antioxidant and reactive oxygen species scavenging properties in the extracts of the fruits of Terminalia chebula, Terminalia bellerica and Emblica officinalis. BMC Complementary Altern Med 2010;10:1-15.

13. Singh B, Sharma B, Jaggi AS, Singh N. Attenuating effect of lisinopril and telmisartan in intracerebroventricular streptozotocin induced experimental dementia of alzheimer's disease type: possible involvement of PPAR $\gamma$ agonistic property. J Renin Angiotensin Aldosterone Syst 2012;14:124-36.

14. Agrawal R, Tyagi E, Shukla R, Nath C. A study of brain insulin receptors, AChE activity and oxidative stress in rat model of ICV STZ induced dementia. Neuropharmacology 2009;56:779-87.

15. Sharma V, Subrahmanya GS, Kumar A. The effect of minocycline on oxidative stress and memory deficits in aged rats. Int J Pharm 2012;2:71-9.

16. Chen Z Hong, XU A-Jing. Reversal of scopolamine-induced special memory deficits in rats by TAK-147. Acta Pharmacol Sin 2002;23:355-60.

17. Vishwakarma S, Goyal R, Gupta V, Dhar KL. GAB aergic effect of valeric acid from Valeriana wallichii in amelioration of ICV STZ induced dementia in rats. Rev Bras Farmacogn 2016;26:484-9.

18. Sachdeva AK, Kuhad A, Chopra K. Naringin ameliorates memory deficits in the experimental paradigm of Alzheimer's disease by attenuating mitochondrial dysfunction. Pharmacol Biochem Behav 2014;127:101-10.

19. Rahman H, Muralidharan P, Anand M. Inhibition of AChE and antioxidant activities are a probable mechanism of Nardostacys jatamansi DC in sleep-deprived alzheimer's mice model. Int J Pharm Tech Res 2011;3:1807-16.

20. Sridharamurthy NB, Ashok B, Yogananda R. Evaluation of antioxidant and acetylcholinesterase inhibitory activity of Peltophorum pterocarpum in scopolamine treated rats. Int J Drug Dev Res 2012;4:115-27.

21. Bhosle V. Anticonvulsant and antioxidant activity of aqueous leaves extract of Desmodium triflorum in mice against pentylenetetrazole and maximal electroshock-induced convulsion. Rev Bras Farmacogn 2013;23:692-8.

22. Azam A, Zaidi SNF. Effect of green tea supplementation on antioxidant enzymes in nephrotoxicity: study in rats. World J Pharm Sci 2014;2:745-51.

23. Kono. Measurement of SOD level. J Boil Chem 1993;5:270-4.

24. Bassil N, Mollaei C. Alzheimer's dementia: a brief review. Leb Med J 2012;60:192-9.

25. Diagnostic and statistical manual of mental disorders. $4^{\text {th }}$ edition. Washington, DC: American Psychiatric Association; 1994.

26. Reed TT, Pierce WM, Maresbery WR, Butterfield DA. Proteomic identification of HNE bound proteins in early alzheimer disease: Insight into the role of lipid peroxidation in the progression of AD. Brain Res 2009;1274:66-76.

27. Norris CM, Kadish I, Blalock EM, Chen KC, Thibault V, Porter $\mathrm{NM}$, et al. Calcineurin triggers reactive/inflammatory processes in astrocytes and is upregulated in aging and alzheimer's models. J Neurosci 2005;25:4649-58.

28. Iqbal K, Alonso AC, Chen S, Chohan MO, El-Akkad E, Gong CX, et al. Tau pathology in alzheimer disease and other tauopathies. Biochim Biophys Acta 2005;1739:198-210.

29. Alzoubia KH, Khabourb OF, Rashida BA, Damajc IM, Heba A, Salah HA. The neuroprotective effect of vitamin E on chronic sleep deprivation-induced memory impairment: the role of oxidative stress. Behav Brain Res 2012;226:205-10. 
30. Yuedea CM, Donga H, Csernansky JG. Anti-dementia drugs and hippocampal-dependent memory in rodents. Csernanskya Behav Pharmacol 2007;18:347-63.

31. Muller T. Rivastigmine in the treatment of patients with alzheimer's disease. Neuropsychiatr Dis Treat 2007;3:211-8.
32. Grundman M. Vitamin E and Alzheimer disease: the basis for additional clinical trials 1-3. Am J Clin Nutr 2000;71:630-6.

33. Sumanth M, Sowmya H, Nagaraj SV, Narasimharaju K. Efficacy of donepezil and galantamine in retrograde amnesia. Asian J Pharm Clin Res 2010;3:23-5. 